\title{
Grinding.
}

\author{
By J. J. GUEST. \\ Note.-The paper was taken as read.
}

THE present day finds the process of machine-controlled grinding firmly established as a manufacturing operation in the works of automobile manufacturing firms, and, believing that the future will witness an increase in the employment of the process, the author proposes to consider what the reasons are which have led to the comparatively sudden development of what is probably the oldest process of shaping metals, so that we may understand the present position and have some idea as to the shape which further developments are likely to take.

The parts of a car now usually ground include external work of circular section, such as gudgeon pins and crankshafts; internal work, such as bushes and cylinders; flat work, such as plates and joint facings; and a variety of miscellaneous work, such as square shafts and cams. As we look back over even a few years, we notice firstly that not only has the quantity, but also the variety of work ground been much increased, and secondly, that machine grinding is now gaining ground on merits quite other than those which originally won it a position in engineering manufacture.

This position was first attained in the machine tool industry owing to the fact that the process met the requirements for such parts as lathe spindles, to be made of hardened steel; and as hardened steel could not be made true otherwise-if we except the doubtful process of turning with a diamond fragment-the grinding machine was devised to attain that end. Owing to the enormous advantage of hardened spindles in machine tools, cost was only a secondary consideration in the operation, while accuracy, as we reckon it to-day, could hardly be considered to be a factor, for the object was to produce a part of hardened steel, with a truth equal to that then produced on soft work by the use of a lathe. While machine grinding continued in this stage, it 
was confined to machine tool and similar work, and in that environment the process made that development which, after quickly adding the merit of accuracy, then added that of economy. To this development four factors mutually contributed, namely, the development of abrasive wheel manufacture, the improvement of the machines upon which the wheels are used, the increased precision of measuring appliances and gauges, and the growth of modern manufacturing methods, with interchangeable parts as a basis, as opposed to the previous mode of production.

As the basis of grinding is the abrasive wheel, we will turn our attention to that first. Its forerunner, the grindstone, has been in use from time immemorial, and to-day it is employed in mechanically operated machines to quite a considerable extent, although the latest improvements in abrasive wheels may render them economical in cases where they have not, so far, been able to compete with the natural stone. There are several varieties of stone in use as grindstones, and these are distinguished by the coarseness or fineness of the grit of which they are composed, and by the hardness of the stone as a whole, the different varieties being suitable for different purposes. In working upon steel and cast iron, however, the natural stone has been almost entirely replaced by artificial wheels made by uniting crushed particles of abrasive material by a cement. As particles of crushed emery are so very much harder than the particles of a natural stone suitable for a grindstone, it would appear to be an easy matter to produce artificially very much more effective wheels, especially as with a strong cement or bond the artificial wheels would be able to run safely at a much higher speed than the weak natural stone. That particular quality of softness of some natural stones, in virtue of which the particles of grit fall out of the stone directly they become the least blunt, so that the face of the wheel always contains sharp grit ready to cut, proved a difficult feature, and has not yet been completely overcome. This feature, combined with the far higher cost of artificial wheels, leads to the natural stone still being used for certain classes of work.

Initially the p:incipal abrasive available was emery, an impure form of corundum, that most in repute as being the purest coming from Naxos; but deposits of nearly pure corundum have since been found, and this is the natural material now most in use.

Corundum is crystallised alumina (aluminium oxide), as are 
the ruby and sapphire, while topaz and turquoise are mostly alumina. The corundum of the Canadian mines is crystalline, and very nearly pure, and the crushed particles have the definite crystalline appearance. Emery contains from 55 per cent to 65 per cent of crystalline alumina, the chief impurity being iron. The crushed particles do not exhibit a definite crystalline appearance, and are of almost any shape. Wheels made of corundum are of a light colour; if emery be used either solely or mixed with the corundum the wheels are of a darker shade, and the dark particles can be seen in them. As corundum is the natural product which stands next to the diamond in hardness, it is clear that there is no direct improvement made in the wheel by mixing emery with the corundum. By the use of the electric furnace artificial, abrasives are now produced, and although their manufacture dates back only a few years, their use is very extensive. The first of these artificial abrasives discovered is termed carborundum (carbide of silicon), and when crushed into particles for the purpose of wheel making, fractures into very keen-edged fragments of distinctly crystalline appearance. The larger crystals appear to have a tendency to form in thin plates, and the hardness is said to be greater than that of corundum, and next to that of the diamond, so that, so far as the material goes, it would seem an ideal abrasive for the formation of wheels, and in practice wheels made of it are generally regarded as being most effective for work on cast iron.

Newer artificial abrasives are alundum and crystolon; the former is used largely, and is probably the best for cortain classes of hard steel. The erushed particles resemble those of corundum in nature of fracture, and are generally of less acute formation than the crushed particles of carborundum. Generally speaking, abrasives differ in hardness, in angle of natural crystallisation, in fracture, in specific gravity, and in resistance to high temperatures. The general cutting power depends upon the hardness and the shape of the edges, the specific gravity affects the speed at which the wheels can be run safely, while it is necessary that a high temperature should not affect them, primarily that they may withstand the heat produced in cutting metal rapidly, and secondly, that they may not be injured by the temperature (about $3,000^{c}$ F.) employed in making wheels by the "vitrifying" process, which produces the best wheels for most purposes.

For grinding out very small holes, steel laps charged with 
diamond dust are used, but it may be pointed out that were crystallised carbon so abundant as to render diamond wheels commercially possible, or should a cheap abrasive harder than the diamond be discovered, the wheels would not be suitable for machine grinding owing to the impossibility of turning them true, unless a harder material still were also discovered. F'or this reason, considering that these new artificial abrasives rank next to the diamond in hardness, it may be doubted whether much further progress can be made in the way of the abrasive material itself.

For the purposes of wheel manufacture, the abrasive is crushed into small particles, and these are then separated into various sizes, by being passed through sieves, the size of the mesh of the sieve giving the name to the size of the particles which were passed through it, but not passed through the sieve with the next smaller mesh. For example, particles which will pass through a sieve the spaces in which are $1 / 24$ th in. square, but not through one in which the spaces are $1 / 30$ th in. square, is called 24 grit, and a wheel made of such particles is said to be a 24 grit wheel.

In the wheel these particles are joined together by a cement or bond. Originally shellac or some gum was used; but the bonds now in use are vitrified bonds, elastic bonds and silicate bonds. The desirable properties of a bond are that it should have a high tenacity, should resist water, soda, oil, or other lubricant useful in grinding, and should be easily controlled as to quantity and distribution in the wheel, and should not be subject to atmospheric influences. As a bond, shellac fails to meet the first two conditions, and has practically ceased to be used; the vitrified bonds meet all the requirements, but for certain purposes the elastic (containing rubber) and silicate bonds have advantages. The elastic (or vulcanised) bond gives wheels about twice as strong as the vitrified wheels, so that where a thin wheel is necessary or desirable, elastio wheels should be used. The vitrified bond gives a wheel with a large proportion of abrasive in it, the amount of bond in some wheels being very small, and the grain of these wheels is very open. Silicate wheels have relatively more bond in them, and the wheels are not so open; also the bond itself is not so strong, with the result that the wheels should not be run at speeds equal to those used for vitrified or elastic wheels. Silicate wheels are further liable to be seriously affected by atmospherie influences. Upon the strength of the bond and its amount depends the 
speed at which a wheel can safely be run, and upon the wheel speed depends the output of the machine, so that the strength of the bond is a factor in grinding efficiency.

In order to determine the manner in which the size of a wheel affects the permissible speed at which it can be run, let us consider the case of similarly shaped wheels. Let $\omega$ be the permissible angular velocity at which a wheel of outside radius $r$ may be run; then $\omega$ will depend upon $r$, also upon the strength $f$ per unit area of the material of which the wheel is composed, and finally upon its density $\rho$. That is, we shall have

$$
\omega=\Sigma a f^{l} r^{m} p^{n},
$$

and if $\mathrm{L}, \mathrm{M}$ and $\mathrm{T}$ are the dimensions of length, mass, and time we shall have

$$
\begin{aligned}
& \quad \frac{1}{\mathrm{~T}}=\Sigma\left(\frac{\mathrm{M}}{\overline{\mathrm{T}^{2}} \mathrm{~L}}\right)^{l} \cdot \mathrm{L}^{\prime \prime \prime} \cdot\left(\frac{\mathrm{M}}{\mathrm{L}^{3}}\right)^{n} . \\
& \text { or } \mathrm{T}=\mathrm{M}^{l+n} \cdot \mathrm{L}^{m-3 n-l} \cdot \mathrm{T}^{-2 l} . \\
& \therefore l=\frac{1}{2} \quad l+n=0 \quad m-3 n-l=0 \\
& \therefore n=-\frac{1}{2} \\
& \text { and } m=-1, \\
& \therefore \omega=a f^{3} r^{-1} p-\frac{1}{2} \\
& \text { or } \omega r=a \sqrt{\rho} .
\end{aligned}
$$

that is, the circumferential velocity of the wheel depends on the tenacity and density of the wheel, and not upon its size.

Although the tenacity depends upon the amount of bonding. material in the wheel, so that a wheel with a large amount of bond may be run faster than one with a small amount of bond, it is usual in practice to say that the circumferential velocity of all wheels should be the same, and to take the rate at 5,000 or 6,000 ft. per minute.

For wheels which have not the same ratio of inside to outside diameter the size of the hole has an effect, but as the wheel has to be driven by flanges holding it on the two sides, this effect is also usually not considered.

In order that a wheel may always present a set of keen particles to the work, after the manner of a soft grindstone, the amount of bond in the wheel must be so arranged that as the presented cutting edges of the particles of grit become dull they shall be torn out of the wheel by the force of the cutting. If there is so much bond as to hold them in position, their edges gradually become dull, and then polished, so that the particles tend to burnish 
the work instead of cutting it. In this case the wheel is said to "glaze."

The amount to which the particles may become dull depends upon the material which is being ground, keener particles being necessary, for example, to cut hardened steel than to cut soft steel, and the amount of bond should accordingly be different in a wheel intended for working on hard steel from that in one intended for work on soft steel. This amount of bond, or hardness of the wheel, is called the grade of the wheel, and is of the greatest importance.

The grades are usually distinguished by letters, which indicate harder wheels as they get further on in the alphabet, $\mathrm{H}$ being a very soft grade and $\mathrm{P}$ a hard one. Unfortunately carborundum wheels have the grades indicated by letters taken in the reverse order. For corundum, the usual grades for work on hard steel are $J$ and $K$, and for work on soft steel $\mathrm{L}$ and $\mathrm{M}$. If a wheel glazes, thereby indicating that it is too hard, or has too much bond in it, it has to be turned up, and if run at a slower speed may work correctly, but if not, the wheel has to be changed in order to grind the work.

While various manufacturers of wheels are able to produce the grade desired in emery and corundum wheels, they appear to have more difficulty in doing so when carborundum is used. I have been informed that carborundum wheels have to be pressed, but there appears no evidence of it in fractured wheels. The silicate wheels do not appear to be so well graded as the vitrified wheels, while there seems to be reason for requiring finer grade divisions in these wheels.

For reasons of safety, finished wheels should have a lead bush, which can be scraped a little so that they are an easy fit on the spindle or collet, and they should be tested at a speed considerably higher than that at which they are intended to be used before being sent out from the factory. Several manufacturing firms make a practice of testing every wheel before despatching it, and this practice should be universally adopted. From the formula above obtained it is to be noted that the stress produced in a rotating wheel is proportional to the square of the circumferential velocity.

In a wheel specification, then, five qualities have to be stated, namely, the outside diameter, the inside diameter, the thickness, the grit, and the grade. The consequence is, that in order to meet any requirement from stock, an enormous number of wheels 
have to be kept on hand. Any lessening of the quantities would, then, be a great convenience. The outside diameter, thickness, grit, and grade must be determined by the particular case, but it could be arranged that wheels of a certain outside diameter should have a certain hole in them, or rather one of two sizes of holes, to meet the style of work for which the wheel is to be used.

If the wheel is to be mounted on a spindle and to remain there unchanged while submitted to much usage, it is desirable, especially from the customer's point of view, who frequently pays the same whether the hole in his wheel is small or large, that the hole should be comparatively small, so that the wheel can be used up as far as possible, even if it has to be transferred to another machine in order to run at a suitable speed. If, however, as is usually the case in machine griading, the wheel has frequently to be changed for another one, it is best to have collets to fit the spindle, and to fix the wheels in different collets, so that when a wheel is changed the collet containing the wheel is changed also. The collets being a good fit on the spindle, the wheels then come up practically true, and very little material is wasted in turning them up in position." This implies a much larger hole in the wheel.

A small series of holes, as in line (b), has been proposed. The line (c) gives a series which the author suggests as suitable for wheels used on collets.

Wheel diameter, inches-

(a) $\begin{array}{llllllllll}6 & 8 & 10 & 12 & 14 & 16 & 18 & 20 & 22 & 24\end{array}$

Hole, inches-

$\begin{array}{llllllllllr}\text { (b) } & \frac{1}{2} & \frac{5}{8} & \frac{3}{4} & 1 & 1 \frac{1}{4} & 1 \frac{1}{2} & 1 \frac{3}{4} & 1 \frac{3}{4} & 2 & 2 \\ \text { (c) } & 2 & 3 & 4 & 5 & 5 & 7 & 8 & 8 & 8 & 10\end{array}$

The knowledge of the desirable properties of wheels as indicated above has been obtained gradually; the early makers, probably partly in the attempt to produce strong wheels, and partly from the view that a wheel which did not wear out quickly was most economical and would please the users, seem to have always made the wheels too hard. Perhaps, however, the soft wheels have done their duty and have been used up, but the very hard wheels are always with us; if they do not wear out because they are so hard, they do not wear out because no one will use them.

The success of the process of machine grinding being dependent both on wheels and machines, the two sections have naturally 
developed together; the machine maker and user determining the desirable properties of a wheel, the wheel maker improving wheels to meet these requirements, and the machine maker again devising possibilities for use of the improved wheels.

The first grinding machines, naturally, would be lathes with a grinding head and spindle mounted on the slide rest, and driven from overhead, a practice still followed occasionally, sometimes for reasons of its small initial cost as plant, and at others for the advantage of performing lathe and grinding operations at one setting of the work. These early machines, and some machines which followed them, which may be considered to be more definitely grinding machines, ground the work dry; they had to use wheels with narrow faces, and employ light cuts for reasons given later.

It is evidently very difficult to obtain good and accurate work with this arrangement, for firstly, stiffness and the necessary fine adjustments were not obtainable in the ordinary lathe, and secondly, if they had been, the grit from the grinding would rapidly destroy the accuracy unless extreme precautions were taken.

Having these early machines in view, it is evident that the first call in a grinding machine is for the protection of its working parts from the waste abrasive. Most modern machines work wet, and this simplifies the problems considerably, and in some machines practically perfect protection is obtained. In the case of machines which work dry, such as small internal grinders, cutter grinders, and some special machines, the difficulty of protecting the slides is very great, but unless the problem is most carefully attended to the machine can have only a very short life, and users should prefer machines which work wet, even if for reasons of depreciation only.

In machines for external work of circular section-plain and universal grinders--the chief difficulty in the protection lies in the table guides for the headstock and tailstock. Both headstock and tailstock should be brought toward the centre to accommodate short work, and they have to be separated fully, while ideally the whole of the table and its ways should be fully protected in all positions. For a long time after grinding was a well established practice, the only mode of protection was a series of guards which had to be adjusted both as to number and position with each change of work length, and which involved careful cleaning of the table whenever the work headstock or the tailstock were 
moved. While this is still the most usual arrangement, there are now several others; on small machines swan-neck headstocks and tailstocks are used, but vibration troubles hinder their employwent on larger machines. The chief essentials are a minimum of overhang and the enclosing of the table towards the wheel, for the wind which is driven centrifugally from the wheel will carry water and abrasive through any opening.

The next difficulty in dry grinding was that due to the heat produced (and with the hard wheels this is very much more than with the later soft, free-cutting wheels), and the temperature effects were considerable. The grinder was then used for work on hardened steel almost entirely, and a piece of hardened steel is practically never straight. In grinding it between the centres, much more would be ground off one side than off the other, and when the work was finished it would be straight and true, but its temperature would be unequal, one side being much hotter than the other; and as the work cooled and the temperature became equal, the hot side contracting would become concave and the work bowed.

The solution of the difficulty is to take a long time over the work, or to let it have frequent intervals of rest, which is economically impossible. In order to distribute the cutting, and so the heat produced, more uniformly over the work and so avoid temperature effects, the work was rotated rapidly, and a narrowtaced wheel was used so as to take a smaller cut. This practice has endured long after the difficulty it was intended to overcome had been removed by the free use of water, but its influence is still at work.

As an example of the effect of the bowing produced, consider a piece of work $12 \mathrm{in.} \mathrm{long} \mathrm{by} 1$ in. diameter; if this is true when the temperature of one side is 50 degrees $\mathrm{F}$. above that of the other side, with a uniform variation across the piece, then, when cold, the side which was previously the hotter will be the shorter by $12 \times 50 \varepsilon$ in., when $\varepsilon$ is the co-efficient of expansion of the material. So that the radius of curvature of the bar when cold would be $1 / 50 \varepsilon$ and the eccentricity at the centre would be

$$
\frac{\left(\frac{1}{2} \times 12\right)^{2}}{2 \times 1 / 50_{\varepsilon}}=18 \times 50 \times \varepsilon=0.0065 \mathrm{in} \text {. approximately, }
$$

a very appreciable quantity on any ground work.

When water was first introduced to keep the temperature of the work low or constant, it was applied in a very small stream, 
and although the above difficulties were reduced, they were not overcome. The amount of water used was gradually increased, until to-day I believe that very little trouble is experienced from temperature effects.

To prevent the water rusting the work and the parts of the machine with which it comes into contact, sufficient soda should be dissolved in the water to leave a slight efflorescence when it evaporates. The addition of a small proportion of soluble oil is an improvement, the finish of the work being rather better, and the tendency to chatter less. The use of the solution necessitates a tank and pump, and the using of the solution over and over again. I believe this to be far better than the use of water from a main supply, as is strongly advocated by at least one firm of grinding machine manufacturers, on the ground that the use of water containing emery in suspension produces poor work, and that the gradual rise of temperature is detrimental.

The second requirement for the progress of grinding was, then, the use of an abundant water supply to prevent temperature effects. It should be noted that the water should be applied to the work as nearly as possible at the point of action of the wheel.

Judging by the difficulties encountered in external grinding before water was freely used, it would have been thought that as the need for internal grinding began to be felt, and machines for the purpose made, they would not have been considered complete without an adequate, though smaller, supply; but few of the machines of to-day are so equipped, and in some of those the water is merely dribbled over the exterior of the work. One recent writer, discussing large internal grinding, points out that the water can be injected into the hole in a stream about $1 / 16 \mathrm{in}$. in diameter.

While dealing with the effect of temperature, it will be convenient to call attention to other causes of "change of axis of work," for any change of axis will cause untrue work, although fortunately the grinding machine is so sensitive as a detector of error that the amount of untruth frequently appears to be very much more than it really is. The most inexcusable cause of change of axis of work is dirt in the centre holes of the work; these should always be wiped out, and for specially accurate work it is desirable to potash them to prevent wear. The ends of the bar should always be faced in the neighbourhood of the centre holes.

With the modern abundant water supply I have never found 
the temperature effects considerable, but no water supply has any effect upon changes of shape of the work due to the release of internal strains by the grinding. This takes place usually in grinding work direct from the bar, particularly if the bar be of bright drawn steel. In material such as this, one side of the material may be under tension and the other under compression, the result being to hold the bar, whose natural position is a bent one, straight; and if a bar be naturally bent and then straightened, it is these internal forces to a certain extent which hold it straight. If, then, the external surface be ground off, the metal under tension on one side and that under compression on the opposite side being removed, the bar is then subjected to a bending moment which promptly strains it, pushing the side which had been under tension in to the wheel.

Similar effects are seen in other shop operations on bright drawn and otherwise initially stressed material; for example, in splining bright drawn bars, or cutting racks on bright drawn squares, or planing cold rolled plates. As an example, some cold rolled strips we machined recently, 32 in. long by 0.2 in. thick, machined to $3 / 32$ in., buckled into an are $1 \frac{7}{8}$ in. high. The machined side became convex, showing that it had been under tension.

In grinding a tool by hand, a trial shows that the forces required to hold the tool in to the wheel and in position on its circumference (not to be carried along by the motion of the wheel) are very small compared with the forces at the tool point of a lathe, and accordingly the early grinding machines were of light construction. The small forces involved, even when the wheel is hard and dull, suggest at once, that as the resulting strain on both the machine and the work are small, the product will have a higher degree of accuracy than that produced by a lathe. This proved to be the case, and the grinding machine, suitably designed and manufactured, with some grit-protecting devices and a water supply, rose to the position of the most accurate of machine tools.

For the purpose of securing accuracy the machine carried the work between dead centres (thereby avoiding errors in the workhead spindle), the main ways both male and female of the main slide were very long, and the table carrying the headstock swivelled, so that when grinding taper work the centres of the machine were co-axial. These points, however, do not belong to the grinding machine as a grinding machine, but were adopted 
to secure the opportunities of accurate work which the comparatively small forces involved in grinding operations, as opposed to cutting operations, offered.

The demands of the rising manufacturing method for accurate tools of all kinds for producing its interchangeable parts, gave an impetus to the art of grinding, and also brought about the improvement in measuring tools, especially the screw micrometer, which had remained almost neglected since Watt invented it, and without which the demand for the product of the grinding machine could not have grown to its present height. The universal grinding machine then became, in shops doing the best work, a pro-

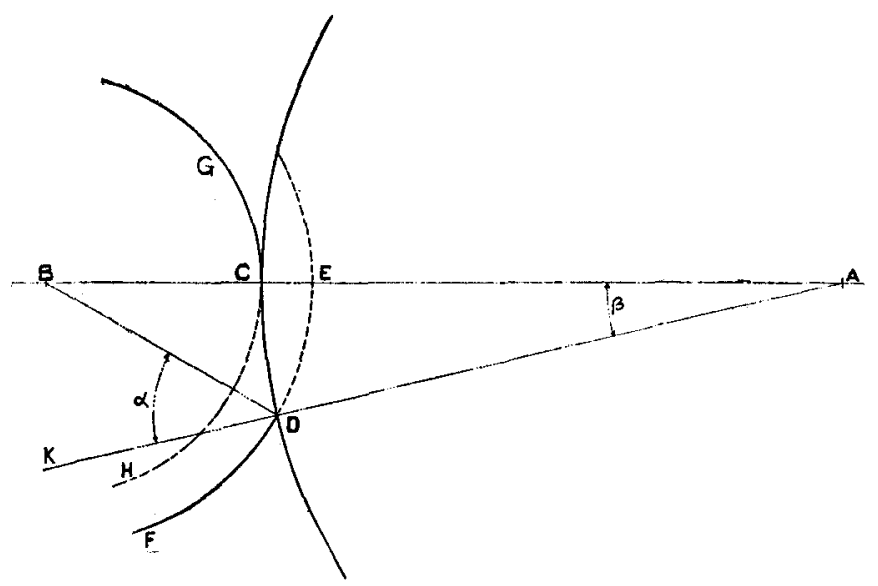

Fra. 1.-Contact in External Grinding.

ducing machine in addition to its function as a tool-making machine, and with the contemporary recognition of wheel requirements, and the improvement of wheels to meet them, gained an economical advantage over the lathe in finishing round work.

This led to the birth of the plain grinding machine, a machine essentially for production purposes, and claiming a position in manufacturing establishments doing work requiring accuracy of two one-thousandths of an inch or closer, on the question of economy, as well as offering the advantages of fine work, finish and accuracy.

Now in these modern plain grinders where output has been designed for, stock can be removed at a speed which is at any rate 
comparable with that at which a lathe can remove it, and it is worth while considering how it is that the actual forces at the grinding wheel face are so small. It is due to the excessively fine cut which is taken by the particles of the wheel, and is in defiance of the fact that the cutting points presented by the particles of grit in the wheel are not of suitable angles for outting the material easily. The magnitude of the chip (for the cutting points produce actual chips) will best be realised if we take a particular example. Let us take the aase of a wheel 14 in. dia. with a 1 in. face grinding a piece of steel 2 in. in dia. The line joining the centres $A$ and $B$ of the wheel and work respectively (Fig. 1), cuts the wheel and work at $C$ : and the wheel has contact with the work o ver the arc CD of the wheel circumference. By the rotation of the work the material is continually being brought up against the wheel face along the line $C D$, EDF showing the unground metal, $\mathrm{GCH}$ the ground surface.

If $\mathrm{AC}=\mathrm{R}, \mathrm{BE}=r, \mathrm{CE}=\delta$ and $\angle \mathrm{BDK}=\alpha$, then we have $\mathrm{AD}^{2}+\mathrm{BD}^{2}+2 \mathrm{AD} \cdot \mathrm{BD} \operatorname{Cos} \alpha=\mathrm{AB}^{2}$,

or $\mathrm{R}^{2}+r^{2}+2 \mathrm{R} r \operatorname{Cos} \alpha=(\mathrm{R}+r-\delta)^{2}=\mathrm{R}^{2}+2 \mathrm{R} r+r^{2}$

$$
-2(\mathrm{R}+r) \delta+\delta^{2}
$$

or since $\delta$ is small

$$
\begin{aligned}
\operatorname{Cos} \alpha & =\frac{\mathrm{R} r-(\mathrm{R}+r) \delta}{\mathrm{R} r}=1-\frac{\mathrm{R}+r}{\mathrm{R} r} \delta \\
\text { or } 1-\frac{\alpha^{2}}{2} & =1-\frac{\mathrm{R}+r}{\mathrm{R} r} \cdot \delta \\
\therefore \alpha & =\sqrt{\frac{\mathrm{R}+r}{\mathrm{R} r} \cdot \delta .}
\end{aligned}
$$

Hence, if $\angle \mathrm{BAD}=\beta$

$$
\begin{aligned}
& \frac{r}{\operatorname{Sin} \beta}=\frac{\mathrm{R}+r-\delta}{\operatorname{Sin} \alpha} \\
& \text { or } \beta=\frac{r \alpha}{\mathrm{R}+r}=\sqrt{2 \cdot \frac{\mathrm{R}+r}{\mathrm{R} r} \cdot \delta \cdot \frac{r^{2}}{(\mathrm{R}+r)^{2}}}=\sqrt{2 \delta \cdot \frac{r}{\mathrm{R}(\mathrm{R}+r)}} \\
& \text { and arc } \mathrm{CD}=\mathrm{R} \beta=\sqrt{\frac{2 \cdot \mathrm{R} r \delta}{\mathrm{R}+r}}
\end{aligned}
$$

and $\therefore$ in our example $=\sqrt{(2.7 .1 / 1000) / 8}=\sqrt{0.00175}=0.0418$, or about $1 / 25$ in.

This is the length of cut below the centre, and if the particles of the grit in the wheel are closer together than this, it will be 
the maximum length of cut, but if they are further apart, the cutting can begin a little above the centre of the wheel. The distance between the particles on the wheel face is very irregular, and depends upon the grit and upon the amount the wheel face has been trued up with a diamond, and varies from 50 to 500 or more per sq. in. of wheel face. Supposing, then, that our wheel has 100 points per sq. in. of its face, and that it rins at $6,000 \mathrm{ft}$. per minute, and each cut is $1 / 25$ in. long, then in one minute $100 \times 6000 \times 12$ of such euts are taken, and if each has an average sectional area $A$, the metal removed is $100 \times 600 \times$ $12 \times 1 / 25 \times \mathrm{A}$ cu. in., and this is equal to the radial depth of cut $\delta$, multiplied by its width and by the surface speed of the work, or $1 / 1000 \times 1 \times 30 \times 12$ if the speed of work is $30 \mathrm{ft}$. per minute. Hence $A=1 / 800,000$ in. It is this excessively fine chip which causes the forces to be so low, and enables the wheel to reduce the dimensions of the work by very minute amounts with accuracy. As the arc of contact is so narrow as only to contain four cutting points on the average at any moment, the total force is very low. As the width of the contact increases (i.e., the $1 / 25 \mathrm{in}$. increases) more cutting points are in action at once.

If we now look at the action from the reverse side, and assume that the machine is taking 2 h.p. to drive the wheel spindle and the work, then as the force at the cutting point is a mutual one and the speed of the wheel is $6,000 \mathrm{ft}$. per minute and that of the work $30 \mathrm{ft}$. per minute, $6000 / 6030$ of 2 h.p. goes to the wheel and $30 / 6030$ to the work, and the force at the cutting point is $P$ in lb. weight, when $\mathrm{P} \times 6000=6000 / 6030 \times 2 \times 33,000$, or $\mathrm{P}=$ $11 \mathrm{lb}$.

This shows just where the advantage of high wheel speed lies, and it is where the artificial abrasive wheel, with its strong bond, gains the enormous advantage which it possesses over the weak natural stone. It points to the value of a strong bond in wheels.

In all kinds of wheels the.cutting edges of the various particles are presented to the work surfaces at very unfavourable angles, and cut at a great disadvantage compared with a correctly-shaped lathe, or other such tool, so that the total energy used, and the total heat produced in removing a given amount of metal, are far higher in a grinding than in a cutting process. The result is that where a quantity of metal is to be removed, the power is a factor to be considered, and sometimes makes the difference between the economy of the two processes. 
Since the are of contact of the wheel and work is an appreciable amount, some room must be provided for the chip of metal, and this is one of the advantages of a wheel having an open grain, such as soft and medium vitrified wheels have. In internal grinding, the arc of contact, as will be seen later, is longer, and this, entailing a longer chip, renders the open wheel more desirable still.

Since the plain grinder was intended for production purposes, the question of output at once became of vital importance; the obvious way to increase this is to widen the face of the wheel and provide for greater depth of cut. Primarily this implied provision for greater power, coupled with a larger water supply, and a proportional increase of rigidity in the machine, but other points also arose in this development.

In order to cover the work surface, the wheel has to be moved relatively to the work parallel to the wheel axis, and if the face of the wheel is not flat and parallel to the main ways the work will have ridges formed in it, or spirals in the case of cylindrical work. To make the wheel face parallel it must be turned up in position with a diamond tool, and for good work nothing else will answer; wheel dressers which act by destroying the surface of the wheel are only suitable for rough work. By fixing the diamond to the tailstock or other part carried by the main slide, this is easily attained with great precision. It may be noted that the diamond tool-holder should be at some, even though small, angle to the wheel face, and that, by turning the tool in its support the same face of the diamond is not always presented to the wheel and worn flat. To get a good wheel surface for finishing work, the traverse of the diamond should be automatic and at the slowest speed, as it cuts with the point only.

Having obtained a true wheel, it is necessary, in order to keep it true, that the whole width of its face should be given equal work to do, so that it wears equally, that is, the side travel per' revolution of the work should be equal to the width of the wheel. Practically this is not quite possible, as it should not exceed this amount, but it should be much greater than half of the wheel, as any less travel than one-half has the tendency to wear the corners slightly round, and then to let the central part grind a slightly shallow set of grooves along the work. As fine feeds were previously used, this necessitated greatly increased table feeds. 
With these rapid traverses, circular grinding work has become a double copying operation, the truth of the ways being copied on to the wheel and then copied on to the work in multiples of the wheel face. For the last traverse or two a slower feed may be used in order to secure slightly greater accuracy and finer finish. If at the end of the travel the main slide reverses promptly, especially at a shoulder where it cannot over-run, there is a large portion of the work surface untouched by the wheel at that reverse (Fig. 2); this can be remedied to a certain extent by arranging the mechanism so that there is a pause before the slide begins to return after coming to rest, so that the work has time to make part or whole of a revolution. The pause should be capable of being easily varied, as it is not always desirable to use it.

A question which is often raised by those unfamiliar with the grinding machine is the effect of the wear of the wheel on the

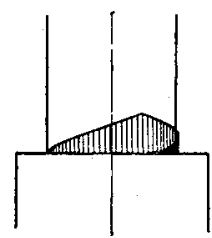

Tarry $\frac{1}{3}$ rev.

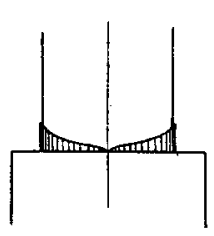

No Tarry.

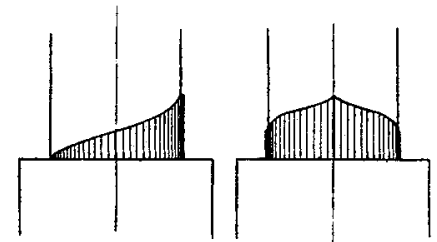

Shaded parts are those remaining unground.

FIG. 2.

parallelism (or desired taper) of the work. Owing to the difference of hardness of wheels and work, and the conditions of use, it is impossible to give any definite rule as to ratio of the volume of metal removed to a given amount of wear of wheel, but it is clear that the wear of the wheel can have no appreciable effect. The traverse of the wheel over the work is rapid, and the diametral depth of cut is small. Supposing that the wheel wears as the cut travels over the surface of a long bar, and that the wear is equal to the feed. At the next feed only the larger diameters are reduced, and so finally the wear is less than the feed. By reducing. the feed, then, the effect of the wear of the wheel can be reduced to less than the amount of the smallest feed; and if this feed is very small, the wear of the wheel is then reduced to a further degree of smallness. Partly for this reason and partly to meet 
the accurney of modern requirements, the cross-feed, which puts the cut on, is arranged to be very fine, a usual amount for the minimum automatic cross-feed being one four-thousandth of an inch on the diameter of the work, or one eight-thousandth of an inch actual movement. It is equally important that the slide should be long, that provision should be made for taking the backlash out of the mechanism, that the feed mechanism should be accurate, and that the parts should be provided with dustproofing and lubricating arrangements. The feed motion should be automatic, not so much from necessity as from the desirability of making the working of the machine easier; it should have an automatic throw-out, and be fitted with a device for altering the position of the throw-out easily, to compensate for wear of the wheel as it occurs, and it is important that both the rate of feed and the total feed to the throw-out should be graduated and easily set.

In the use of machines so arranged for larger output, difficulties then arase from vibration, showing itself as chatter marks on the work. These chatter marks take the shape of small flats, and are usually very shallow and of dimensions which would be of no importance in lathe work, but occasionally they are of a more serious nature, and when once started they tend to become worse,

If the chatter is caused by the work, steadies must be applied to hold it stiffly; but apart from this, the most usual cause is want of truth in the wheel, and the first thing to be done is to true the wheel afresh, and, if possible, use it without stopping the spindle or changing its speed. At the same time the spindle bearings should be felt for play and for temperature, as to secure good work the bearings should be elosely adjusted and should run warm, and should they be at all loose, chatter marks are apt to result. If chatter marks still occur they are due to vibration causing changes in the distance between the axis of the wheel and that of the work, which may occur either in the machine or in the work. As regards the machine, it may be due to a heavy fastening, or lacing in the belt to the wheel spindle; this belt should, if possible, be an endless one with cemented joints, and both the stretch of the belt and the movement of the wheelhead should be compensated for, and the tension kept at the correct amount by a weighted idle pulley; even the flap of a loose belt is sufficient sometimes to produce marks on the work. Similar effects, but occurring at every revolution of the spindle, are pro- 
duced by the wheel or spindle being out of balance, the forces produced being comparatively large owing to the high speed.

Although in light machines everything may run sometimes entirely satisfactorily, in order to minimise the trouble which may every now and then occur, and reduce this to insignificant limits, the wheelheads and spindles should be heavy and substantial, and the whole machine braced and ribbed for stiffuess. Sometimes a very slight cause will set up vibration, owing to parts of the machine having the same vibration period as the disturbing effect; when this is suspected, the work speed, or wheel speed, or both, should be changed, and these speeds should not be arranged in any very simple ratio, so that if one speed causes a synchronising effect, this can be avoided by using the next speed.

The steadying of the work presents a difficulty owing to the continual decrease of the diameter as the grinding proceeds: the steady should bear on the work at two spots-opposite to the wheel, and underneath the work axis, but rather nearer to the wheel axis than the work centre is: the steady should not bear on the work in a continuous are. Adjustment should be provided, so that the steady bears at both the spots, and, as the work decreases in diameter, the steadies must be promptly adjusted to bear again, as, if the work is only prevented from chattering by the use of the steadies, the chattering will commence immediately, they are the least amount slack, and if the work is nearly to size the marks may not be ground out when the size is reached. The adjustment of the steadies was at first made by means of screws, and these had to be continually adjusted by the worker of the machine to meet the decrease in diameter of the work, and this required his whole attention to be concentrated upon the machine while the work was in progress. These were followed by an arrangement of springs which spring the work in towards the wheel, the force being capable of fine regulation; to prevent the springs continuing to press the work into the wheel after the desired size was reached, a stop screw is provided. This practically is a sizing device in addition to the cross-feed of the machine, and the stop screw has to be of very fine pitch and very accurate to meet the limits usually required in the work; the stop screws have frequently to be adjusted to compensate for the wear of the parts of the steady which bear on the work.

The latest development is the automatic steady, which bears on the work with a slight constant force, und moves towards the 
work as it decreases in size, while a continuous ratchet consisting of a ball moving in a tapering race positively prevents the work from moving back. These require very little attention from the operator beyond the initial setting, and leave him free to attend to the other requirements of the machine.

When very slender bars, such as thin camshafts, have to be dealt with, vibration will take place in the work between the supporting; steadies; in order to prevent this, the work should be sprung upwards, the strain preventing the bar from vibrating. The con " tact of the lower part of the steady extends towards the wheel; the

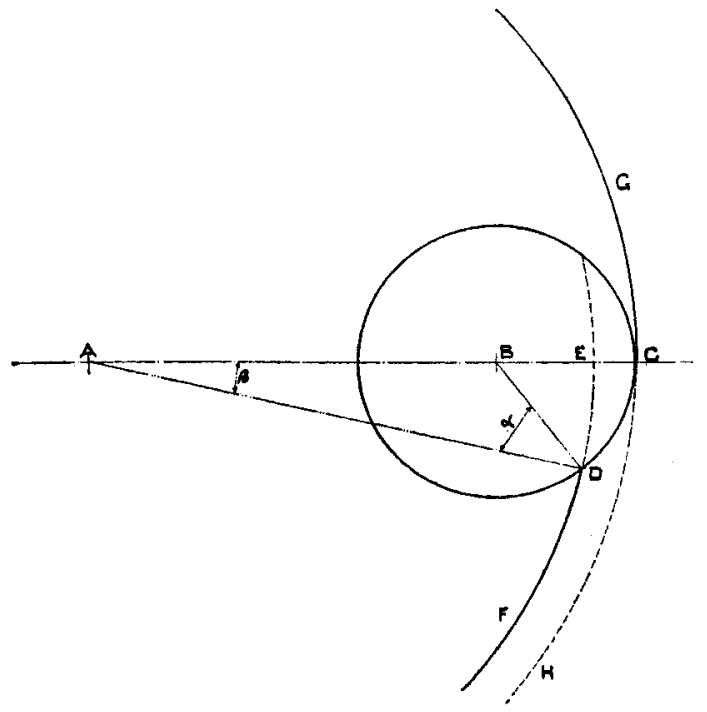

Fro. 3.-Contact in Internal Grinding.

For referenco to letters see p. 339 .

bar as it is sprung up is withdrawn a little from the wheol and it is then forced towards the wheel by the other adjustment screw of the steady. The size of the bar at the two ends is determined by the cross-feed of the machine, while the size at each steady bearing is controlled by the corresponding steady screw.

Such developments have now established the grinding machine as affording the most economical mode of producing much external work. The efficient wheels and high power of the present-day machine euable parts in many cases to be manufactured from stampings more cheaply than they can be by any other method. 
When we turn to internal work we find that the machines were later in being developed, which is to be expected, as the problem presents difficulties of another and apparently more intractable type. The difficulties lie chiefly in the machine, the only difference in the actual grinding operation being the greater arc of contact of the wheel and the work (see Fig. 3).

As the grinding wheel has to be small, it should be as large as possible initially, so as to give the maximum amount of usable material. This gives a long arc of contact between work and wheel, and if we take as an example a three-inch hole being ground by a two and a half inch diameter wheel, with a one-thousandth of an inch depth of cut, the are of contact is (working as before) about one-eighth of an inch. For this reason and because the spindles must of necessity be small in diameter (requiring that the force should be reduced as far as possible), the wheels used should be softer than those used for external work.

As regards the machine, the workhead spindle is now live and has a most important effect on the accuracy and quality of the work, and the grinding spindle presents several points of difficulty, particularly when it is to be used on small work. Unless the grinding spindle end carrying the wheel overhangs from its bearings by at least the depth of the hole to be ground, the space for the wheel-end bearing of the spindle is very much oircum. scribed. This renders the adjustment arrangement, dust protection and lubrication of the bearings, and also the water supply, if the machine grinds wet, difficult.

In the case of small holes, these difficulties lead to the employment of overhung spindles, and this in turn introduces the diffculty that, as the spindle must be small in diameter so that the bearings do not give trouble owing to the high speed of the spindle necessary to give a reasonable speed to the circumference of the wheel, the overhung part of the spindle is apt to be springy. It also multiplies, by its overhang, the effect of any defects in the bearing. The length of the hole which it is possible to grind commercially is, therefore, very limited.

With somewhat larger holes, the spindle bearing is carried as near to the wheel as is consistent with reasonable dust-proofing. The lubrication devices have usually to be of an elementary. character as there is little room for oil tubes. The spindle bearings have to be of small. diameter so as to run without trouble at the requisite speed, but this is also necessary in order to leave 
room for the sleeve supporting the bearings and for adjustment, and it does not now involve the spring caused by the overhang of the previous case. It may here be noted that to give $5,000 \mathrm{ft}$. per minute to its circumference, a 1 -in. wheel must be run at 19,000 revs. per minute, or over 300 revolutions per second. The size of the sleeve which contains the spindle and bearings must be considerably less than the diameter of the hole to be ground, as a reasonable amount of wheel wear must be provided for, more especially as these small wheels are relatively expensive.

When this reasonable amount of wheel wear is provided for, space is easily found for a tube which will carry a small wator supply.

The high speed necessitates very considerable accuracy in the workmanship of the parts, and of the spindle especially, if the apparatus is to run well. To minimise the effect of errors, the spindle is frequently made in two parts comnected by a double tongue, or the part of the spindle connecting the two journals is made sufficiently thin to be flexible. The first construction may involve unexpected side thrust on the bearing, the amount being: larger as the size of the coupling diminishes.

With a further increase in the size of the hole to be ground, the difficulties become less, as there is then room for substantial bearings with good adjustment and lubrication. Since the stiffness of the sleeve increases as the fourth power of its diameter, and decreases as the cube of its overhang, the whole construction, for the customary ratios and depth of hole, is more rigid. The supply of water becomes more necessary in these larger machines, but until a recent period none of the machines ground wet.

For the sinaller machine; ball bearing spindles have been experimented with; the spindle can then be overhung from the bearing without incurring the danger of spring in the spindle itself, for ball bearings run so freely that very high speeds can be attained with comparatively large diameters of spindle. Furthermore, the contact between spindle and balls, and balls and race, being metal to metal, there is little or no slack in the bearings to be multiplied by the overhang of the wheels. The trouble appears to be due partly to the high speeds and partly to temperature effects, and although the advantages alluded to above should give every inducement to grinding machine makers to produce a satisfactory one, the makers' catalogues and advertisements 
do not illustrate them. This, however, does not prove that satisfactory spindles using ball bearings cannot be produced.

As the rate of revolution of these small spindles is so high, too long a life should not be expected from the bearings; for example, the spindle carrying a 1 in. wheel makes as many revolutions in 6 months as a spindle taking a $14 \mathrm{in}$. wheel makes in 7 years. The author considers that in these fast-running spindles the best plan is to make the wearing parts of as cheap a design as possible, so that renewals do not have to receive serious consideration.

For such work as engine cylinders, where a number are cast together, so that it is inconvenient to rotate the work, the whole internal grinding spindle and its bearings are arranged to rotate round a parallel fixed axis, and the distance between these axes is made variable for the purpose of putting on the feed of the wheel to the work. For constructional purposes this variation is usually arranged by carrying the grinding spindle eccentrically in a sleeve also set eccentric to the fixed axis, so that rotation of the eccentric sleeve puts on the cut. This arrangement has the disadvantage that the cut produced is not proportional to the turn given to the eccentric sleeve, but its rigid construction compared with the alternative arrangements which have been tried, has led to its retention. The machine was originally developed very many years ago for the purpose of grinding the holes in locomotive rods.

After round section work, the type most frequently met with in grinding is flat work, and for this three or four methods are in use. The first is to grind the work by mounting it on a rotary face plate, and setting the face plate axis perpendicular to and intersecting the wheel axis, and traversing the wheel relatively to the work. By adjusting the angle until the wheel cuts equally on the two sides of the face plate axis the work can be got flat within very close limits. The second is to mount the work similarly, but to set the axes parallel and simply bring the work and wheel together, using a cup wheel. There may be some difficulty in getting the work quite flat at the centre as the wheel wears, but for collars and other work with a central hole the method is a rapid and satisfactory one. The arrangement is extensively used in grinding metal slitting saws, the necessary concavity being produced by setting the axes at a small angle to one another. If the cup wheel edgre passes through the axis of the work, the resulting ground surface is spherical. One advantage of this method for the manu- 
facture of saws is that for a given edge clearance less metal is removed from the work, giving a stiffer saw, and taking less time.

A third method of producing flat work is to use the wheel mounted in a manner similar to that of a tool in a planing machine, the flat surface being perpendicular to the lines of the two slides. This should be the most accurate of the methods in use, but it suffers from the disadvantage of being the slowest, and so has not found large employment.

The fourth method is to mount the work on a slide, and a cup

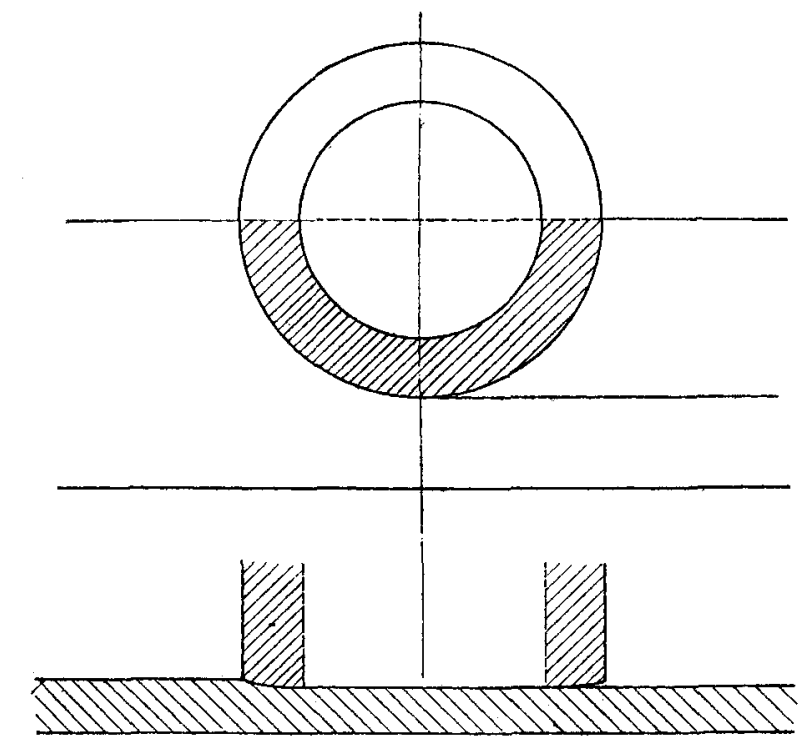

Fra. 4.-Diagram showing Wear and Contact of Wheel in Surface Grinding.

wheel on a spindle perpendicular to the line of the slide. This is a convenient method for such work as squared shafts, which can be ground between centres, so that surfaces square with one another are easily obtained. The second and fourth methods, using a cup wheel, are suitable for rapid production. They do not give quite such accurate work as the other methods, but the accuracy is fine enough for almost all purposes. An examination of the work will show at once, by the shape of the marks of the wheel, which of the methods have been used in doing a particular piece of work. 
The important difference between the use of a cup wheel and. the ordinary disk wheel consists in the arc of contart of the wheel with the work, for where in the first example given for external round work the action of a cutting point was over about one twenty-fifth of an inch, and for internal work over one-eighth of an inch, it may now be over several inches.

The foed of the work surface to the wheel is also in a different style. The material to be ground off is fed up to the curved edge of the wheel; which becomes rounded by wear and the cut then becomes more distributed over the radial face of the wheel, and a very considerable area of the wheel comes into action (see Fig. 4). This large number of particles in action simultaneously inplies greater output, and domands the supply of greater power. Under these circumstances, each particle taking a very long cut at each revolution of the wheel, the particles individually do more work, and becoming dull, should become detached from the work rapidly. This, by the large area of contact, they are not free to do, and so continue cutting when dull. This further increases the power required, and renders still softer wheels necessary. Owing to the disadvantage caused by the retention of the particles, the dullness may make the wheel refuse to cut, and besides dressing the face, it is advisable to reduce the area of contact by chamfering the wheel on the internal edge.

The grit should be large and the bond very soft. The chips taken by the cutting points are long pieces of fine seotion, and collect in the settling tanks as a kind of steel wool.

Silicate wheels are suitable for this work, but whatever wheel is used, the grade must be right within a close degree. If the wheel is a little too hard, the rate of output suffers owing to the causes above mentioned, while if the wheel is too soft, it will wear a way so rapidly that the cost is a serious matter. It is very desirable to consider the cost of wheels in this form of grinding, and to suit them very exactly to the work in hand.

In cases where the amount of metal to be removed is large, the face wheels have been formed of pieces of grit stone inserted in a chuck, securing the soft stone of low cost, and running it at a reasonably high speed.

In grinding tools with edges, such as knives, shear blades, and metal slitting saws, the employment of a cup wheel has the advantage that there is no tendency to slightly round the edge as tho whoel passes over it. 
Face wheels may be used for other: work, such as grinding cams, where the contact of wheel and work is over a small area or linethe cutting action is then similar to that in ordinary external or internal grinding, and the grit and grade of the wheel are selected on the same basis.

The thrust bearing of the wheol spindle is of first importance in all machines taking face wheels. The distance between the bearings is also a point to be considered, as the cutting action takes place at some distance from the wheel axis. The whoels being of a cup or cylindrical shape with thin walls should not bo run at quito the same speed as ordinary disk wheels, and a metal band which can be olipped round the wheol close to its eutting edge and easily moved back as the wheol wears is a desirable safeguard. There are several chucks on the markot which grip the wheel by compression on the outside, but the usual mode of mounting them is to cement them into a collet.

So far we have considered work done by wheels trued to a flat face, but wheels may be trued to a curve and reproduce that curve upon the work-for example, ball-races and fillets on crankshaft pins are usually ground that way.

When, as in these cases, the curved edge to be ground is of circular section, the wheel and work after having been fed together may be moved relatively so that the shape is formed mechanically; and in this case the operation is similar to external or internal grinding with line contact. If, however, the wheel and work are merely fed into contact with one another for the cut and then moved so as to grind the sectional shape over an area, the grinding operation is under rather different conditions and may be termed "form grinding." For example, the whole pin of a crankshaft with its two fillets may be ground by rotating the pin and feeding in the wheel already trued to the shape; or a ball race may bo ground in a similar manner. This method of grinding has a tendency to leave linear marks on the work due to slight imperfections in trueing the wheel. As the wheel is partly used on its side, the spindle thrust bearing is of importance, and should be arranged as near the wheel as is practicable, and the collet flanges should extend well up the sides of the wheel.

In order to keep its shape well, the wheel should be of as large a diameter as convenient, and the trueing mechanism, whother pantagraph or other, must be rigid and arranged so that a minimum of time is last in the operation of trueing the wheel 
and adjusting it to work again. In considering the accuracy with which the wheels can be trued, it must be remembered that the diamond or carbon wears, and as pure corundum and the new artificial abrasives will be preferred as the material of the wheels as being harder than emery (and so the wheels made of them will keep to shape better) the idiamond will wear more rapidly than on the older emery wheels. When a flat of any size has been worn on the diamond the wheel will chatter as it is used, and it has to be reset with another corner ready to eut, hence the forming device must be arranged that the cutting point of the diamond can be easily adjusted to its correct position. The wheel in form grinding cuts under good conditions, and the output should be good, and since in many cases the operation is mechanically simple the use of this method will probably increase considerably.

Further examples of this method which are of interest in motor work are the grinding of worms and gears, and the bottom of the ways in shafts for castellated fits.

In the above survey of the development of manufacturing grinding we have noted the difficulties which have occurred, and how these have been overcome, and the knowledge of natural facts obtained in this search for improvement serves as a guide in problems which may arise. As the art of grinding now stands, it affords the best means of manufacturing some machine details when regard is had to cheapness of production only, of very many when quality and cheapness are considered, and for some details it is a necessary process. The advance which has been made in the development of the process from the stage where it was a costly operation, only used where unavoidable or extremely desirable, to a stage where it is in competition with other means of production on the matter of cast only of the product, and where it gives the added qualities of finish and truth of product, has resulted in changes of design of the product, and enabled parts to be made of harder quality, or of hardened steel, where previously they had been soft, and has enabled bearings to be reduced in size owing to the surfaces produced being closer to the geometrical surface desired. With increasing precision of its parts, the speed of a machine may frequently be increased without trouble from noise and vibration, and with the increase of speed, when the question is one of power and not of force transmitted, the parts may be reduced in size a little further.

These differences of design are not only due to the maker, but 
also to the user of the machine, who by his demands turns the newer design into the necessary one. In considering the advisability of grinding instead of machining parts in other ways, these points are to be considered-for although the cost of a detail part is always a consideration, yet the product has to be sold, and the user is to be considered at each step.

Added to this the process has proved to be one of increasing economy, and hence we may feel fairly assured that the demand for improved machines, and for the machines now beginning to be used for flat and form grinding, will repay the efforts of the pioneers in these lines, and thus lead to growth of the process. As any improved wheel finds a ready market, there is no doubt but that the manufacturers of wheels will employ their efforts to improve the manufacture of the wheels, the bonds, and the abrasive materials, although we cannot expect any very great improvement in the latter. 


\section{THE DISCUSSION.}

The President: In calling on you to commence the discussion, I think we are very much indebted for the manner in which Mr. Guest has put the paper before us, for in avoiding reading it verbatim from the paper, he was able to give us the facts in his own words, and in a still more interesting form. I am quite sure that the author of the paper can answer a lot of the difficult points which most of us have found in connection with a branch of the industry which has come into practical shape since the large majority of us served our apprenticeship.

Mr. L. H. Pomeroy, in opening the discussion, said: I should be glad to know whether the author can give us a few figures for what he considers to be the possibilities of grinding as a means of removing so many cubic inches of metal per minute. It is easy enough to get figures from manufacturers' catalogues on this point, but so far as my experience goes, these have to be decreased by about 50 per cent in order to get a true estimate of the real state of affairs. I think all here are practically interested not only in motor cars, but in all the various components of motor cars, so that we are dealing with objects which, so far as grinding, and particularly external grinding, is concerned, vary from a $\frac{3}{8}$ in. spindle up to a 2 in. crank shaft, that is over a range of comparatively limited sizes. We are also dealing with classes of material which do not vary greatly in composition, i.e., from ordinary mild steel, with a small carbon content, to nickel-chrome steels of the 50 or 60 ton ultimate tensile strength variety, and I have been wondering whether it would be possible for the author to give us in tabulated form the actual speeds and feeds used for the various sizes and qualities of material which are used in ordinary motor car engineering. If we had this information it would give us something to check the results which we get in our own shops, and this would, I think, be distinctly useful. The distortion caused by the springing of materials mentioned in the paper, occurs sometimes when grinding crank shafts from stampings of nickel-chrome steel, and I have found one or two rather surprising cases. In one instance, when an engine was put on 
a test bench and run, we found exceedingly heavy score marks on alternate sides of the crank shafts. The trouble was evidently due to the severe internal stresses in the crank shaft when in the rough state. I now rough grind the crank shafts, and give them a week's rest on the top of the case-hardening furnace to eliminate these internal stresses.

Although the author has said that the forces which exist in ordinary grinding machines are only small, in a crank shaft grinder I know it takes the best out of a 15 h.p. motor to get the stone into the shaft, and I think that in that case the forces between the work and a stone of $20 \mathrm{in}$. diameter and $2 \mathrm{in}$. face must be very much grelater than the author has indicated. I should be glad if ho would give us some information upon the subject of form grinding which he mentioned in his paper. We all know the trouble of noisy gears, and I have had information that there is a gear grinder that has been put upon the market in this country. I am sure that if there is such a thing as a reliablo and accurate machine of this sort there is a future for it, as the only other process which at all competes with grinding, as far as $I$ know, is the Vickers case-hardening process, with which there is no distortion.

Another point upon which I should like information is the subject of grinding cam shafts. The majority of motor-car makers use cams which have a hollow face. The cam is made up practically of two circles, with a hollow face. Some time ago we purchased a cam shaft grinding machine to deal with these hollow faces. The first difficulty was that we could not use a wheel larger than 1 in. diameter, because the largest internal radius on the cam was only $\frac{9}{16}$ in. This made the process 50 slow that it failed. We re-designed the cam and made it $1 \frac{1}{2} \mathrm{in}$. internal radius, so that we could use a larger wheel. In this grinding machine the cam former, upon which the cam form is expanded radially, is about 9 in. diameter. There is a roller in contact with this cam former, which transmits the radial motion of the cam to the wheel spindle. The trouble which we experienced was that due to the wear of the wheol, because directly wear takes place the shape of the cam is altered entirely. We used a series of rollers to overcome this trouble, but in the end had to give up the method since it seemed to be impossible to obtain accurate results thereby.

The cams are now milled, the whole cam shaft is hardened, $\mathrm{z} 2$ 


\section{(Mr. L. H. Pomeroy.)}

taken to the grinding machine and ground on the journals; at the same time the base of the cam is ground by turning the shaft by hand through a given angle, which is the base angle of the cam. If $\mathrm{A}$ is the point of contact between the two circles when the cam is roughed out and milled, we grind it with a wheel about $10 \mathrm{in}$. diameter, and run that wheel round until the dotted line from $\mathrm{A}$ to $\mathrm{C}$ forms the actual base of the cam. That gives a beautifully quiet cam, since the result is that at $\mathrm{A}$ and $\mathrm{C}$ there is a gradual step to the cam, which means that slack in the tappet is taken up before lifting the valve.

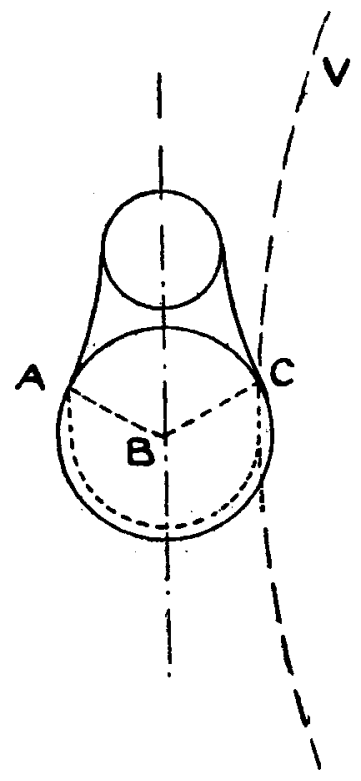

Fig. 5.

Prof. C. V. Boys: I am unable, Mr. President, in answer to your invitation to speak, to say anything that is worth hearing. I had the advantage many years ago of being taken by the author through his own works, and there I was able to see what beautiful work he was doing. He undoubtedly possesses in high degree the instinct of construction and design for exact work of this kind, and I have been greatly interested in his paper. I would only say that his title "Grinding" should be "Wheel Grinding," for grinding includes that branch of the general subject that I know more about which is mainly used by opticians, i.e., where two 
things are ground together. This is only used by members of this audience in the roadside occupation of grinding valves.

The author has raised many points of interest worthy of discussion, but I regret I am unable to add anything useful.

Col. R. E. B. Crompton: I am afraid I can only speak from my laboratory experience. I have done a good deal of grinding work on machinery for making accurate measurements, and I have met with considerable difficulties in grinding correctly close up to collars on shafts. Can the author give us a little further information on this subject, as he has only hinted at it in his paper? I shall be glad also if he will enlarge a little on the point as to the relative speeds at which the work itself should be revolved in relation to the angular velocity of the abrading wheel.

Mr. W. Deakin: I think the author has been very clever in dealing with the subject, considering the position that he occupies in connection with the manufacture of grinding machines. No one would suspect from the paper, and the manner in which the subject has been presented, that he had any commercial interest in this matter. I very much appreciate the analytical manner in which the author has dealt with the basic principles of the subject, and the valuable information he has laid before those who realise the importance of wheel grinding in the production of mechanical work.

It could not be expected that the author would give us an elaborate detail of costs on this subject of grinding, and I think that this side of the question will have to be left to each of us in his individual capacity in his different industry; the important feature is the way in which the author has pointed out the reasons which exist for certain things that we observe, and that portion of the paper which deals with the question of the manufacture of wheels must, I think, be very enlightening and helpful to those engaged in this branch of industry.

Mr. F. L. Martineav: I have to use a large amount of work on which grinding is desirable, and $I$ find it is very difficult to get it done satisfactorily. A great difficulty seems to be in getting internal grinding done accurately, and I should very much like to hear of a machine which will grind either cast iron or steel internally without the work having to be rotated and the feed being put on while it is rotating. There are machines of that kind, but I do not know of one which can be used with 
(Mr. F. L. Martineau.)

water running over the work, and there is a great difficulty in cast iron when dry grinding is employed, because in many cases particles of the grinding abrasive are left in the pores of the iron. This is a trouble which has been brought to my notice very forcibly during the last few years. The production of ball races by grinding is a subject which has had a great deal of attention lately, or at any rate during the last few years, and it is very interesting to examine under a microscope a ball race which is supposed to have an absolutely perfect finish. I was looking at one the other day, and I thought I was looking at a ploughed field. The surface of the race is generally very rough, as compared with the surface of the ball, and I should like to ask the author whether he thinks that is due to the use of dry grinding almost exclusively for the production of these races. If the surface of the race could be made as smooth as that of the ball, I should think the frictional resistance of the bearing would be considerably reduced, and also that its life would be prolonged.

Mr. Claud Crompton: I gather, from what the author has told us, that chatter marks on the work are entirely due to the vibration of the work itself, and not to the vibration of the wheel. I should like to know exactly if that is so, because in grinding I have found it is very difficult to get rid of chatter marks in some circumstances, and though I have tried to prevent them by stopping the vibration of the work, yet still this has not stopped the chatter marks. In reference to form grinding, the author said that when a wheel is formed to a particular shape, and pushed straight into the formed piece of work, it would act under very favourable conditions, but I have found a difficulty in that the wheel cannot be kept up to the right shape. In some ball races which $I$ have had to grind, it is very important that a cone-shaped piece should be not only of the correct diameter, but also of the correct shape; these pieces, which are made on an automatic machine, are not correct to shape before they are ground, with the result that the wheel gets continually out of shape. The only means I know of keeping it to shape is to continually true up the wheel to a template, which is only a rough and ready method of doing it. I should like also to supplement Mr. Martineau's query as to how to make ball races with a smooth polished surface. I have tried using, as a finishing cut, a fine oilstone wheel, which appears to give good results, but I 
have never been able to ascertain what is the proper method to pursue.

Mr. E. G. E. Beaumont: I should like to supplement the question asked by the last two speakers in reference to the finishing or polishing of ground surfaces. I know of some instances where journal sleeves running in phosphor-bronze bushes, when finely ground, were not satisfactory. They would not unfrequently seize and cause trouble, and it was not until they were finally polished and finished that they were really satisfactory. In the case of fairly large diameters precise accuracy is not essential, but in the case of the ball bearings mentioned by the last two speakers, the necessity of working to fine limits is absolutely essential.

Mr. W. A. Tookex: I should like to ask one question which has reference more particularly to the material which is used in the manufacture of grinding-wheels. We have been told in the first part of the paper of three materials, emery, corundum and carborundum, and it is said that the latter is, if anything, better than the natural products of omery and corundum. But is it not a fact that carborundum is a very much more difficult material to bind? I believe that the natural rock, emery and corundum, has a more flinty and more irregular surface, which better lends itself to the bonding medium, and is more tenaciously held, whereast carborundum, being a product of the electric furnace, has a slippery surface, and is more difficult to retain in the wheel. The question is important, because it affects the safe speed at which a carborundum wheel may be run. There ought to be some differential factor of safety, as it were, for the different qualities of wheels, and perhaps the author can tell us the proper peripheral speed for each material. It must not be overlooked that effective grinding also depends upon three human factors, namely, the emery wheel manufacturer, the grinding machine manufacturer, and the user. Occasionally, users give their order's for wheels more or less blindly, not really knowing what is best for their particular kind of work. I think if the author would give us a few hints upon the ordering of wheels for particular uses it would add very much to the value of the paper he has given us this evening.

Mr. L. H. Hounsfiedd: I should like to ask the author how we should distinguish between vitrified wheels and silicate wheels? I am afraid, in my ignorance on the subject, I thought they were 


\section{(Mr. L. H. Hounsfield.)}

the same. With regard to grinding such parts as crank shafts, if a shaft is made in case-hardened steel, whether built up or made from one piece, of course, grinding has to be resorted to, and I suppose with steel in that hard state there is not much fear of particles getting embedded in the surface. When, however, a crank shaft is made of fairly soft steel, say 0.4 per cent carbon, is there not a possibility of particles of grinding material being embedded in the surface of the soft steel in the same way as in the case of the soft steels commonly used for cutting, grinding and polishing? If so, does a crank shaft, which has been ground up in this way, wear its bearings more quickly than a shaft which has been turned and finished with a turning tool?

Mr. E. A. RaIner: There is only one point I have to make, and that is with regard to form grinding. So far as my experience of grinding has gone, really satisfactory form grinding can only be obtained by moving the surface of the work along a path of the samo shape as it is intended that the work shall ultimately take. In that way absolute trueness on the side of the wheel can be dispensed with. The work traverses the shape to which it has to be finished, and it is more or less immaterial, within limits, whether the wheel was the exact shape of the path or not. I found that especially so in the case of gears, and to some extent with cams. I believe, in working with this process, it would be possible to make a cam of the form shown in Fig. 5 without working with a wheel of the exact diameter, and I should like to know whether the author considers that it is really a cure, so far as the shape of grinding is concerned, to traverse the work and not depend on the wheel.

The President: I would like to ask one or two questions myself, because I have had to find out what I could about grinding in the past, on other work a great deal more difficult than anything which turns up in automobile practice, and that is in connection with the moulds used in type founding machinery, the degree of accuracy in which has to be considerably finer than anything in motor car work. One piece of work I had to do in particular was the Wicks rotary type casting wheel. This was a disk $20 \mathrm{in}$. in diameter, with strips 3 in. long let in round the periphery on one of the flat faces so that the circular disk to be ground was made out of a hundred sectors, built together with narrow gaps between them. These sectors were of hardened steel, held down with screws of ordinary mild steel 
and steady pins of soft tool steel driven in to hold them in their place, so that in the length from end to end there were six on seven changes of average hardness in the material. There was soft mild steel, soft tool steel, and hard tool steel. At first sight it appeared almost impossible to grind that surface truly flat, and the thing certainly looked very nearly hopeless, but we got over it by making a special machine for the job. To get the requisite accuracy in some of this work we employed a grinding spindle made with extreme accuracy, which depended only on the air film in the bearings, and not on oil lubrication, to keepl it running without liability to shake. The principle on which these spindles run was not my own invention or discovery, but was a method which had been employed in some watch making machinery in use at Prescot. I do not know whether the author has had experience of work of such high degree of exactitude, but it is an extremely difficult piece of work to grind up a surface $20 \mathrm{in}$. outside diameter and $14 \mathrm{in}$. inside diameter when the maxinum error must not exceed one ten-thousandth of an inch. Much depends on the material and grade of the wheel, and having found one which did the work we used it till it was nearly worn out, when on examining" the label we found this had become illegible, and we had to send a man to all the likely sources of supply of emery wheels in London to try and find a wheel which would exactly match it, and we had a great deal of difficulty in doing this. Meanwhile we tried grinding wheels of all sorts of materials, and each one we tried seemed to be worse than the last. I think the author should be able to give us a very great deal of information as to what material is best for dealing with composite surfaces and also for those materials most largely used in automobile construction.

One machine which, though not strictly coming within the terms of reference of the paper, yet does a great deal of plane work, is the disk grinder, which is used now in every miotor works for taking off material from aluminium, gunmetal, brass, cast iron and steel casting as well as stamped and forged steel. It takes off a lot of material in a short time, and euts away the material more quickly than any other class of machine I know of. But to get the best results, the disk has to be covered with one abrasive substance for cutting steel, and another kind for cutting cast iron, while yet another kind will cut better on gunmetal, and perhaps the author will give us information as to the 
best materials to use as abrasives on the paper disks adapted to this class of machine. Perhaps, also, he will say something of interest regarding the functions of grinding material when used under these conditions, which are more like what was known as lapping in the past, the ancient method used by the diamond polisher and eutter for centuries past. In motor car work a lot of grinding has to be done on cast iron, and it is always difficult to get rid of the last traces of the abrasive material from the small soft places or pores that are always present in the surface of cast iron. In tool steel there is not nearly the difficulty; paraffin and other things will get rid of the abrasive, and it is always possible to get a clean surface, but in the soft classes of material to which the use of grinders has now been extended the abrasive material does hang about and tend to cause premature wear, and anything the author can itell us as to methods of removing the final traces of abrasive material will be of interest to us.

Mr. J. J. Guest, in replying on the discussion, said: Mr. Pomeroy has asked a question on the subject of the times of grinding operations, in particular as to the number of cu. in. of metal removed per minute. This is a pertinent matter, but it is rather a difficult one to treat in a general way, and it should be especially remembered that removal of stock, or roughing, represents only one portion of the time occupied. There are a number of points which control the time of grinding a component part.

The first problem which arises is the allowance to be left on the part: if soft, to allow for grinding only, if to be hardened, to allow for distortion only. The best allowance depends on the grinding machine, and with modern high powered machines it should be from 15 to 25 thousandths of an inch on soft work and more on hardened work according to its shape. Formerly, allowances were less, but experience has tended to increased allowances, as, with modern machines, the time of the grinding operation is only slightly increased while the saving in the lathe is considerable. The allowance, however, naturally affects the time of grinding; the greater the allowance the greater the amount of material to be removed.

After the piece has been roughily ground to a small amount over size, it has to be finished to a certain degree of accuracy, or limit of error, and to a required surface. The limit of error 
being different for the various classes of fits, the time of finish grinding will be different; for example, it will take longer to finish a part to a push fit than to a running fit.

Other causes affecting the time required are the nature of the material, the shape of the part, the quantities and the particular machine used, its rigidity, accuracy, handiness and the power supplied to it.

Mr. Pomeroy mentioned that the sizes occurring in motor work varied from $\frac{3}{8} \mathrm{in}$. to $2 \mathrm{in}$. in diameter. It is very difficult to state a time for the small articles without actually seeing them. The larger sizes are less influenced by varying conditions, and a rule which will cover them (and larger diameters still) is that

$$
\text { time }=\frac{1}{2} l d+l+d
$$

when $l$ is the length of the work, $d$ its diameter, both in inches, and the time is in minutes.

The time for this fornula is a time for bonus work, and if half the time saved is allowed to the workman it will give him a 25 to 30 per cent bonus. While not a mathematical formula, it is near enough for general practice. It is for work of first rate quality and accuracy, and includes allowances for micrometering the work, trueing the wheel and setting the machine for small quantities.

The formula must not be used for jobs presenting difficulties inherent in the job itself', for instance, long thin shafts such as thin cam shafts. For if the ratio length to diameter is considerable ( 25 or more) and the accuracy 'close, the work has to be sized at each steady, and it will take longer than the formula would give. Also work with shoulders, or of small lengths and diameters, would take a little longer, chiefly owing to relative increase of time required for handling and gauging.

The above is the sort of "time" I suppose that Mr. Pomeroy asks for, as it gives what he can reasonably expect in practice. There is, however, another sort of "time," namely, the time the maker of the machine will probably state as the time in which the machine will do the work. This is quite a different amount. All makers of machines have to come up to the same mark, so to speak, except for the handicap of conscience, and all have to do the same. If $\mathrm{A}$. quotes a time, $\mathrm{B}$. has to try to quotel a time of some kind which sounds a bit better. This leads to a test in which everything is set ready and all adjustments prepared on the machine. A start is taken on a stop watch, and then if 
(Mr. J. J. Guest.)

anything goes wrong the test is scrapped, and it does not matter whether the job is scrapped also.

As Mr. Pomeroy says, these times are somewhat misleading.

Large quantities affect the time very favourably, and-speaking. now as a maker of machines-we have had some surprises as to the reduction of time which practice on particular work leads to. In particular, we once quoted the time of twenty minutes for a job somewhat like a cam shaft; reckoning to start prepared, with machine set, steadies in position, atc., and to just get a good job in the time. We heard nothing for a long time from our customers, and then we were favoured with a call. Everything seemed quite satisfactory, except that there was a curious error in the machine, as the work was a shade taper at the two ends. As all the machines are carefully tested for accuracy before going out, the suggestion rather staggered us. Shortly afterwards, however, we enquired whether the machine turned out the work in the time guaranteed, and our customer had no doubts on that point. Referring to his figures, he gave us eight minutes as the actual time. It was then elear what caused the taper; but we could not get near that time, taper or no taper.

On small work especially, quantities make a difference. With a machine which sizes accurately, no time need be lost in gauging, all the measuring being done after the work has been removed from the machine and while the machine is grinding another piece. Three carriers should be used, so that one piece is always ready to put into the machine.

With regard to speeds and feeds, these have to be arranged with regard to the particular machine used. Some machines will only take a narrow faced wheel, while others use wheels several times as wide, and certain work has to be ground with a narrow faced wheel. Generally, to get the maximum output, the widest wheel the machine will take should be used, and a slow work speed and a traverse of the table equal to from $\frac{2}{3}$ to $\frac{4}{5}$ of the width of the wheel per revolution of the work.

As other members have asked questions as to the relative speeds of wheel and work, I would point out that wheels should generally be run at as high a surface speed as is consistent with safety; if, however, the wheel glazes at this speed, it may sometimes be made to cut properly by reducing the speed; the wheel then behaves as if it were of a softer grade. For disk wheels the circumferential speed should be from 5,500 to $6,000 \mathrm{ft}$. per minute. 
If this speed is given to the wheel when full size, it falls as the wheel diameter lessens by wear; after an certain reduction the next higher speed on the machine can be used, and the wheel again runs at the full circumferential speed. For cup wheels the speed should be much lower, and 3,500 to $4,000 \mathrm{ft}$. per minute is suitable.

The work surface speed is independent of the wheel speed, and, according to modern practice, should be between 20 and $40 \mathrm{ft}$. per minute. I consider that the surface speed should be increased with the diameter in proportion to its square root; or, if the power supplied to the machine be then insufficient to take the previous cross feed, that the speod be increased to a less extent, and the depth of cut slightly reduced. Opinion and practice, however, favour running the work at the above surface speed irrespective of its diameter. The high speeds in use some years ago were adopted in order to minimise temperature errors, which are now avoided by the use of a good water supply. With regard to the distortion of parts owing to relieved stress, this takes place both during machining operations, and slowly afterwards. If an originally bent bar be straightened, it is bent the reverse way to its original bend until it has gone beyond the straight shape, so that when it is released the elastic restoring forces leave it straight. But these elastic restoring forces leave the material of the bar in a stressed condition. In the straightening process the material at the outside (away from the neutral surface) is taken beyond the yield point, while the central material is not stressed to the yield point; in the elastic effect after release, the overstressed material is strained in the opposite way by the restoring action of the central material. If the bar is then ground, the outer material is removed, and as it no longer bears the stress, the elastic forces in the rod then bend the rod and rearrange themselves. The greater part of this action takes place immediately, but a slight action goes on slowly for a considerable period afterwards. The best precaution lies in annealing, and Mr. Pomeroy's method of giving the crank shaft a week's rest on the top of the case-hardening furnace should be effective. Our practice is to boil the parts, which is also an efficient method, and the temperature reached is known-an important mattor in the case of hardened parts.

With regard to the cutting force at the wheel edge in a grinding machine having a wheel 20 in. diameter by 2 in. face and taking 
(Mr. J. J. Guest.)

15 h.p., if the whole power were delivered at the wheel edge running at $6,000 \mathrm{ft}$. per minute, the tangential force would be $15 \times 33,000 / 6,000$, or $82 \frac{1}{2} \mathrm{lb}$. But in order to produce good work, the wheel spindle and its bearings must be almost metal to metal, with very little oil between, so that a considerable amount of power is required to run the spindle; in addition, power is absorbed by the belts, and in other ways. Knowing the spindle and pulley diameters, the loss cannot be exactly calculated, as it depends upon the setting up of the bearings; but, taking dimensions in common practice, the least possible loss is 5 h.p., and the probable loss about 7 h.p., so that the force cannot be greater than $55 \mathrm{lb}$, and is probably $45 \mathrm{lb}$.

I havo examined a number of gear grinding machines, and amongst them that apparently referred to in one of the questions; they come under the head of form grinding machines, but I do not consider that it is desirable that $I$ should here criticise any special machine. The same would apply to the cam grinding machine as a whole, but I would say that the method of grinding shown in Fig. 5 is not what I term "form grinding," for the cam is ground using the cylindrical edge of the wheel, and the form is produced by a copying process. Under the head "Form Grinding," I propose to include those cases where the wheel is trued to a special shape, using a pantograph, or other mechanism, for producing the shape, and then the section of the article ground is produced by the shape already formed on the wheel. To produce werk continuously true to shape by this method the wheel has to be continually kept true, and it is easily seen that the method will not be capable of producing such accurate work as that which can be produced by the wheel itself being mechanically moved relatively to the work, though in this method any but the simplest forms introduce new difficulties connected with the wear of the wheel. Form grinding, however, is sufficiently accurate for much eommercial work, and the machines necessary are comparatively simple.

Several questions have been asked as to ball race grinding. The best practice is to use machines grinding the race by swinging it relatively to the wheel, so that the section is mechanically formed: the wheel should be trued to the same shape. This corresponds to ordinary straight (and taper) cylindrical grinding -the "cones" or inner races to external work and the "cups" or outer races to internal grinding. 
Ball races, however, may be ground by trueing the wheel to the shape required and bringing the work into contact with it until the race is ground. This is "form grinding"; it is not so accurate as the former method, and is apt to leave circular marks on the race, but the machines are simpler and the post is less.

In actually grinding the ball races, our practice is to grind them as carefully as possible, and then to polish them highly with crocus, or similar powder. The ball races we manufacture are those used in our internal grinding spindles, the smaller sizes of which run on balls. As the speed is very high the surfaces have to be true and of first-rate quality. In order to grind the parts truly the wheel must cut freely with little pressure, so that a soft wheel is used, and the ground surface when magnified would present the appearance of a series of cut marks. It is the function of the polishing process to polish away the high parts of the marks and to leave a level, smooth surface. As the parts rotate round their axis while being polished, eircular marks. are apt to show in the finished race under the microscope. The surface obtained is not quite so good as that of a good commercial ball, as the balls lend themselves more readily to the polishing process. The balls, however, also show defects.

I have frequently examined work under the microscope for traces of emery or other abrasive, but have never found any in hard or soft steel, and there does not appear to be any tendency for this to occur when modern free cutting wheels are used. In the case of cast iron, however, the surface usually appears to be full of small cavities into which it is practically possible to examine and in which the abrasive could easily lie. I cannot suggest any simple and effective method of getting rid of traces of emery lodging in these holes, but would recommend a good supply of water to be used in the grinding, especially for internal work.

When two rubbing surfaces get grit between them, it is the harder surface which usually suffers, the grit becoming embedded in the softer material and cutting the harder one.

When ground journals give trouble the lubrication should first be looked to, as ground work is so near to the greometrical surface that sometimes the lubricant cannot find sufficient entry. It is not due to any defect in the ground surface as a ground surface, for the best running bearings both for speed and load are ground. 
Chatter marks on the finished surface are a common difficulty, and in reply to $\mathrm{Mr}$. Claude Crompton I would say that they are due to variations in distance between the work and the wheel axis, and can, therefore, arise either from the work or from the machine. To prevent vibration of the work steadies are usually supplied with plain and universal grinders. These support the work directly from the table. The most efficient is the automatic steady, as it keeps in contact with the work continuously although the work diameter decreases. When the chatter arises from the machine, it should be eliminated by following the course indicated in the paper; slowing the work speed may assist, also reducing the width of the cutting face of the wheel. Finally, a wheel of a different (softer) grade should be tried.

Another practical point raised, refers to the method of grinding up to collars and shoulders. The first thing to be noted is that the machine must reverse accurately, and the second is that the wheel must be kept flat on the side towards the shoulder. It must also be trued on its side towards the shoulder. When the reverse takes place at the shoulder end, there should be a pause, or tarry, before the main slide begins to move, thus allowing the work to make a complete revolution or thereabouts. As the movement takes place, the wheel tends to wear on the side away from the shoulder, and at the next reverse there should be no cross feed, so that the wheel has no serious cutting to do on its movement towards the shoulder. This keeps the wheel flat on the side next the shoulder, so that by throwing out the cross feed at the reverse when the wheel is at the other end of the traverse, the wheel is kept flat towards the shoulder and so the work is ground straight up to the shoulder, without that slight taper which occurs when the cross feed takes place at both ends. The wheel should not be allowed to run into the shoulder at the reverse, but should stop just short of it, and finally the shoulder just taken into the wheel by hand. When the truth of the shoulder is of importance, our practice is to turn the wheel head through a small angle, take all end play out of the spindle, true the face of the wheel true with the main ways and a little of the side of the wheel towards the shoulder square with the main ways, and after finishing the body of the work as described above, run the shoulder of the work against the side of the wheel and then traverse the wheel outwards from the work.

In reply to the query as to the comparison in cost between 
finishing work by grinding and in a capstan lathe, I would in turn ask the question, Why, if the capstan produces a part satisfying the requirements, should it be ground? The problem always is how to produce a part of good enough finish and precision at the lowest price. If a part does not require great accuracy, or special surface, make it in a capstan, so that it is finished and does not need grinding at all. But if a higher degree of accuracy is necessary, the part will be made partly on a lathe and then finished on a grinding machine: usually roughed out in a capstan, or hexagon turret, lathe for economy's sake, but sometimes in a centre lathe. It will then be more accurate and almost certainly cheaper than if made in a lathe alone. In short, the capstan lathe and grinding machine are not tools to be opposed to one another, but rather partners in the work of production, and I consider that the grinder is a machine which supplements the capstan lathe more than it does the centre lathe. The costs are not to be opposed to one another: if the article is good enough when produced on a capstan, use a capstan, as the part cannot be produced more cheaply than by that means; and if it is not good enough, it can be roughed out in a capstan and finished in the grinding machine.

Occasionally it is more economical to grind directly from the bar or forging, but these cases are limited to those in which the article is of simple shape and the quantities so large that drop forgings close to size can be produced at a low cost. Roughingout in a centre lathe can be dispensed with sometimes when the article is springy. Plain cam shafts in tough steel can be best produced by grinding directly from the black bar, and drop forged crank shafts of suitable design can be profitably treated in the same manner. 